\title{
A FORMAÇÃO DE PROFESSORES PARA O ENSINO MÉDIO: VELHOS PROBLEMAS, NOVOS DESAFIOS.
}

\author{
Acacia Zeneida Kuenzer*
}

\begin{abstract}
RESUMO: Este artigo tem como objeto a formação de professores para o ensino médio. Parte do pressuposto de que a formação de professores, à medida que se constitui em estratégia de reprodução do capital, não se separa da esfera da produção, com o que há propostas diferenciadas e desiguais que atendem às diferentes necessidades de formação para o trabalho; em decorrência, reduz-se a autonomia relativa das propostas pedagógicas. A partir desse pressuposto, mostra que o capitalismo forma seus professores primariamente, no âmbito das relações sociais e de produção, e secundariamente, mediante cursos de formação inicial e continuada. Analisa os dados relativos à formação inicial e ao perfil do professor e referencia as políticas, as diretrizes e as propostas do Plano Nacional de Educação para o período de 2011-2020.
\end{abstract}

Palavras-chave: Formação de professores. Docência no ensino médio. Trabalho docente no capitalismo.

\section{High SCHOOL TEACHER TRAINING: OLD PROBLEMS, NEW CHALLENGES}

ABSTRACT: This paper focuses high school teacher training. It assumes that, since it is a strategy to reproduce capital, teacher training cannot be separated from the sphere of production. Thus, different, unequal proposals try to meet the different needs of training for work. The autonomy of the pedagogical proposals is thus reduced. Based on this assumption, the text shows that capitalism primarily prepares teachers in the framework of social and productive relationships, and secondarily through initial and continuing training courses. It then analyzes the data on initial training and teacher profiles and confront them to the policies, directives and proposals of the National Education Plan for 2011-2020.

Key words: Teacher training. High school teaching. Teaching work in capitalism.

* $\quad$ Doutora em Educação e professora titular aposentada do Programa de Pós-Graduação em Educação da Universidade Federal do Paraná (UFPR). E-mail: acaciazk@uol.com.br 


\title{
LA FORMATION DES PROFESSEURS DE LYCÉE: VIEUX PROBLÈMES, NOUVEAUX DÉFIS
}

\begin{abstract}
RÉSUMÉ: Cet article a pour objet la formation des professeurs de lycée. Il présuppose que, en tant que stratégie de reproduction du capital, la formation des enseignants ne peut pas être séparée de la sphère de la production, de sortent que des propositions très différentes et inégales essaient de répondre aux divers besoins de formation pour l'emploi; il en résulte une réduction de l'autonomie relative des propositions pédagogiques. A partir de cette hypothèse, le texte cherche à montrer que le capitalisme forme ses enseignants principalement dans le cadre des relations sociales et productives et, en deuxième lieu, dans les cours de formation initiale et continue; Il collecte ensuite des données sur la formation initiale et le profil de l'enseignant et les associe aux politiques, directives et propositions du Plan national d'éducation pour 2011-2020.
\end{abstract}

Mots-clés: Formation des professeurs. Enseignement au lycée. Enseignement dans le capitalisme.

\section{Introdução: a formação de professores como campo de disputas}

$\mathrm{E}$

m que pese o amplo debate que vem se desenvolvendo nos últimos vinte anos sobre a formação de professores para o ensino médio no Brasil, esta questão continua longe de ser enfrentada adequadamente, ao se pretender mudar uma realidade que vem se arrastando há décadas. Entre as muitas divergências, há pelo menos alguns aspectos sobre os quais há consenso: a escassez de professores, notadamente em algumas áreas e regiões, a insuficiência e a inadequação das políticas e das propostas para esta formação e seus severos impactos sobre a qualidade de ensino.

Já sobre as políticas e programas de formação inicial, não só não há consensos que permitam agregar as organizações da sociedade civil em torno de uma concepção mínima, que permita um adequado enfrentamento das propostas que vêm sendo implementadas a partir das diretrizes curriculares, na direção de um projeto mais integrado às necessidades e especificidades da maioria da população, como também os investimentos têm sido insuficientes diante da dimensão do problema.

Se os estudos já vêm apontando os problemas relativos à formação de professores de ensino médio de educação geral, a situação se agrava com a proposição, pela Lei n. 11.741/2008, da modalidade que integra ensino médio e educação profissional.

O enfrentamento desta crise só será possível com a compreensão de seus determinantes mais amplos, o que implica a adoção de uma perspectiva de análise que se debruce sobre os problemas reais de forma radical, buscando delinear suas causas históricas e suas determinações estruturais, como ponto de partida para a construção de alternativas a partir de outro campo hegemônico. 
Esta afirmação já aponta para uma primeira questão preliminar: a do ponto de vista que orientará a análise, uma vez que, no modo de produção capitalista, as categorias se situam em campos antagônicos: do capital ou do trabalho. Na perspectiva do capital, a educação se constitui em processo permanente de disciplinamento, tendo em vista a produção e a reprodução, naturalizada, da mercadoria. Na perspectiva do trabalho, o que está em jogo é o enfrentamento crítico das determinações estruturais do capitalismo, cuja superação demanda não só a sua apreensão e compreensão, mas também o desenvolvimento e a disseminação de uma concepção de mundo contra-hegemônica, que confira organicidade às ações de transformação do modo capitalista de produção e reprodução da existência.

Mesmo considerando os limites de uma educação contra-hegemônica, é preciso reconhecer seu espaço como possibilidade histórica, uma vez que se utiliza de categorias de análise que permitem ultrapassar as aparências para apreender e compreender os problemas reais a que estão submetidos os que vivem do trabalho pelo modo de produção capitalista.

Assim, nunca é demais reafirmar que as transformações na materialidade são inseparáveis do desenvolvimento contínuo de uma consciência revolucionária, o que só pode ocorrer mediante processos ampla e especificamente educativos, comprometidos com o desenvolvimento de consciências críticas, não individualizadas, mas capazes de organização coletiva (Mészáros, 2008). Partindo dessa premissa, se no capitalismo há projetos educativos antagônicos, no bojo das relações sociais e produtivas não há um projeto único, ou neutro, de formação de professores, independentemente do nível, da etapa ou da modalidade de educação que esteja sendo analisada.

Talvez seja este o primeiro desafio a enfrentar: superar a falsa consciência da suposta neutralidade das políticas e propostas de formação. Mesmo considerando que o espaço da formulação e implementação de políticas é um campo de disputas, o campo da formação de professores tem sido tratado por sobre as diferenças de classe, como se o simples fato de exercer a profissão docente isentasse esses profissionais de valores, concepções e compromissos de classe. Ou, como diria Gramsci (1978), como se fossem intelectuais tradicionais, que se colocam acima das diferenças de classe, buscando educar a todos para o bem comum.

A exceção a esta compreensão, no campo do trabalho, é feita por alguns movimentos sociais, que têm buscado formar seus professores a partir de seu próprio projeto contra-hegemônico, como o Movimento dos Trabalhadores Sem Terra (MST). Já no campo do capital, constatam-se experiências pedagógicas que determinam processos de formação de professores que objetivam formar trabalhadores para o capital, como vem fazendo o Sistema S. Contudo, de modo geral, a questão vem sendo tratada no campo da suposta neutralidade de uma ação docente que se desenvolveria por sobre as diferenças de classe e apesar delas. 
O processo pedagógico em curso, no entanto, não é universal; é preciso elucidar a quem ele serve, explicitar suas contradições e, com base nas condições concretas dadas, promover as necessárias articulações para construir coletivamente alternativas que ponham a educação a serviço do desenvolvimento de relações verdadeiramente democráticas.

Em resumo: se há projetos pedagógicos contraditórios, consequentemente não existe uma única proposta de formação de professores, mas propostas que se diferenciam a partir das formas históricas de organização e gestão do trabalho, visando atender à divisão social e técnica que o trabalho assume em cada regime de acumulação. Ou seja, há demandas desiguais e diferenciadas de formação que se estabelecem ao longo das cadeias produtivas, nas quais se confrontam finalidades e interesses que são contraditórios.

Estas diferentes propostas de formação, por sua vez, dada a materialidade das relações capitalistas em que se inserem, se objetivam em práticas tão contraditórias quanto são as relações sociais que as geram, não se reproduzindo em sistemas puros, mas sim em práticas que mesclam dimensões conservadoras e progressistas. Ou seja, mesmo que, na ponta da formação, a proposta seja marcada pelos interesses hegemônicos ou contra-hegemônicos, as condições materiais de sua realização, pela sua natureza capitalista, determinam práticas contraditórias.

\section{O cenário da formação de professores: os dados, as políticas e as diretrizes}

O Censo Escolar da Educação Básica de 2009 (INEP, 2011) mostra que, dos 461.542 professores que atuam no ensino médio, em todas as redes, 91\% são formados em curso superior, sendo que $87 \%$ são formados em curso de licenciatura. Considerando os que têm formação superior, $95,7 \%$ deles são licenciados, o que evidencia significativo avanço, no sentido do cumprimento das determinações da LDв de 1996.

Quanto ao perfil, a metade se declara branca, 75\% atuam exclusivamente na rede estadual, 95\% atuam na área urbana e situam-se majoritariamente na faixa de 33 a 50 anos, aproximadamente $50 \%$ ministram uma única disciplina e $84 \%$ atuam em um único estabelecimento. Chama a atenção o reduzido número de professores que atuam na rede federal de ensino, aproximadamente $2 \%$, e dos que atuam exclusivamente na rede privada (16\%); somados os que atuam também nas redes federal e estadual, este percentual sobe para $20 \%$.

Em resumo, caracteriza-se um perfil que, em parte, repete o do alunado do ensino médio (Kuenzer, 2010b): branco, urbano, disciplinar e inserido na rede pública estadual, majoritariamente em um único estabelecimento. 
Os números relativos à formação, se analisados globalmente, refletem uma situação aparentemente satisfatória; contudo, a desagregação desses dados, a par de seu cotejamento com a realidade do ensino médio, aponta uma realidade bastante preocupante.

A análise desagregada dos dados mostra, entre outros fatores, a desigualdade da distribuição da qualificação entre as disciplinas, fato que vem sendo reiteradamente apontado nas últimas décadas. Assim, apenas $53 \%$ dos professores que atuam no ensino médio têm formação compatível com a disciplina que lecionam.

Segundo estudo realizado pelo Instituto Nacional de Estudos e Pesquisas Educacionais (INEP, 2009), a disciplina mais crítica é Física, em que apenas 25,7\% têm formação específica; Química, Artes e Língua e Literatura Estrangeira têm aproximadamente $40 \%$ de professores com formação específica; nas demais disciplinas, à exceção de Educação Física, onde este percentual é o mais alto $(77,2 \%)$, o percentual de professores que têm formação específica fica entre $50 \%$ e pouco mais de $60 \%$.

Esses dados, por si sós, evidenciam a necessidade do esforço intensivo na formação inicial de professores. Contudo, ao considerarmos a baixa taxa de atendimento aos jovens pelo ensino médio e as metas de expansão propostas pelo PNE, relativas à universalização do atendimento a toda a população de 15 a 17 anos e à elevação da taxa líquida de matriculas para $85 \%$ nesta faixa etária (Meta 3), realmente o quadro da escassez de docentes se agrava. Ao considerar ainda a inconformidade das associações científicas da área da Educação com essa meta, a partir da realização do III Seminário de Educação Brasileira pelo Centro de Estudos Educação e Sociedade (CEDES), em Campinas, em abril de 2011, o quadro se agrava ainda mais. A proposta das associações é que se assegure a universalização do ensino médio independentemente da faixa etária, uma vez que a meta, ao limitá-lo à idade de 17 anos, exclui a maioria dos jovens que estão fora desta faixa etária, 135 milhões aproximadamente, sendo que, destes, cerca de 80 milhões não concluíram a educação básica.

Outro dado a considerar diz respeito à disparidade entre o número de licenciados formados nos últimos 25 anos e o número de licenciados que efetivamente atuam na educação básica, que fica entre 30\% e 40 \% na maioria das áreas. Em Educação Física, disciplina em que há maior compatibilidade entre exercício e formação, apenas 16\% dos licenciados atuam no ensino médio (INEP, 2007).

Conclui-se, portanto, que embora o déficit atinja, com os dados deste mesmo ano, 235.135 professores - considerando todas as disciplinas -, apenas a ampliação da oferta de formação em cursos de licenciatura não garante o atendimento às necessidades do ensino médio, uma vez que a maioria dos licenciados não atua como professor. 
Há várias, e conhecidas, explicações para esse fato; embora a Resolução n. 01/ 2002 do Conselho Nacional de Educação (CNE) tenha determinado que a licenciatura é um curso com identidade e não mais um complemento do bacharelado, muitos alunos optam pela dupla graduação, por meio da complementação, por entender que a licenciatura pode abrir uma possibilidade de trabalho quando o bacharelado não o fizer.

É preciso considerar, também, que as licenciaturas têm sido uma boa opção para os trabalhadores que pretendem ter um curso superior, mas não pretendem trabalhar na área; ou que há crescimento, no mercado, da oferta de licenciaturas com qualidade discutível, que não viabilizam o ingresso na carreira docente pela via dos processos seletivos. Ou a hipótese mais consistente talvez seja a baixa atratividade da carreira, em face da sua desvalorização social: baixos salários, precárias condições de trabalho, precário nível de profissionalização, alunos cada vez menos comprometidos, baixo reconhecimento, alto nível de estresse e crescente intensificação das tarefas.

Enfim, os dados apenas reiteram o que tem sido constatado nas últimas décadas: a política de formação só tem sentido quando integrada à estruturação da carreira docente, à politica salarial que assegure a dignidade do professor e à garantia de condições adequadas de trabalho.

A formação de professores para atuar no ensino médio integrado merece atenção especial, uma vez que esta tem sido considerada a modalidade que melhor atende aos jovens oriundos da classe trabalhadora.

Uma rápida visita aos dados relativos aos docentes do ensino médio integrado mostra a reduzida proporção dos que atuam nesta modalidade, restrita em seu maior número à rede federal. Os dados revelam algumas especificidades: o número de docentes que atuam nesta modalidade é reduzido, mesmo no âmbito da educação profissional. Dos 58.858 docentes que atuam na educação profissional, apenas 15. $915(27 \%)$ são exclusivamente do médio integrado; acrescentando a estes os que atuam nas modalidades concomitante e subsequente, o percentual vai para $35 \%$.

Ao comparar este total com o total de professores que atuam no ensino médio de educação geral, tem-se que os professores que atuam no médio integrado correspondem a apenas 4,5\% daquele total. Também, entre os docentes que atuam na educação profissional, é maior o número daqueles que não têm licenciatura, o que corresponde a $65 \%$.

Ou seja, com a meta de expansão do ensino médio integrado, o grande esforço de formação de professores será nesta modalidade, problema que se agrava com a controvérsia acerca das propostas para sua formação inicial. Está em curso, no CNE, a discussão da Proposta de Diretrizes Curriculares Nacionais para as licenciaturas 
em educação profissional e tecnológica, que tem como relator o conselheiro Francisco Aparecido Cordão. Ressalte-se, contudo, que há muitas divergências sobre esta questão, uma vez que as propostas para discussão incluem desde a licenciatura para técnicos de nível médio até a pós-graduação lato e stricto sensu, passando pela licenciatura para quem já tenha concluído bacharelado ou curso superior de tecnologia e pela licenciatura integrada ao curso superior de tecnologia; e, ainda, mantém a existência dos Programas Especiais de Formação de Professores para a Educação Profissional (Resolução CNE/CEP n. 02/1997) e prevê a possibilidade dos pedagogos atuarem nos cursos da sua área. A falta experiência profissional seria substituída por estágio de prática laboral a par do estágio em docência, como se isso fosse suficiente para, substituindo a experiência, atender à necessidade de articular teoria e prática mediante o trabalho docente.

Já se escreveu em outro texto que a formação de professores do ensino médio integrado só é diferenciada quando se trata das disciplinas específicas da formação profissional. De resto, os docentes são formados nas licenciaturas já existentes. Contudo, ao se tratar da formação dos docentes que vão atuar nas disciplinas específicas, a situação se complexifica, pois as pesquisas têm evidenciado que a qualidade deste professor resulta da articulação de conhecimentos tácitos, científicos e pedagógicos, o que não se pode resolver com um curso genérico de licenciatura e sem que haja alguma forma de articulação com o mundo do trabalho, pela experiência ou pela pesquisa (Kuenzer, 2010a; Urbanetz, 2011).

Configurada a situação atual, a continuidade da análise remete às políticas, havendo duas dimensões a considerar: a assunção pela CAPES, a partir de 2007, da responsabilidade de subsidiar o MEC na formulação de políticas e do desenvolvimento de atividades de suporte à formação inicial e continuada de profissionais que atuam na educação básica; e as metas do PNE para o período de 2011/2020.

A ação da CAPEs se desenvolve mediante vários programas que apoiam a integração entre as instituições de ensino superior públicas ou comunitárias sem fins lucrativos e as escolas de educação básica, financiando o desenvolvimento de inovações, materiais didáticos, práticas dos licenciandos e cursos de pós-graduação lato e stricto sensu, mediante custeio e bolsas. Em janeiro de 2009, o Decreto n. 6.755 instituiu a Política Nacional de Formação do Magistério da Educação Básica, com o que foram criados os Fóruns Estaduais de Apoio à Formação dos Profissionais da Educação e o Plano Nacional de Formação de Professores da Educação Básica.

Os resultados desses programas, dado o seu caráter recente, precisarão ser avaliados no que tange à sua efetividade, em termos de impacto das ações na qualidade do trabalho escolar, uma vez que a qualificação individual do professor não necessariamente resulta em melhoria dos indicadores de qualidade do trabalho da escola média. Essa avaliação é necessária, dado o volume de investimento nesses 
programas, pois já há estudos específicos sobre a formação continuada de professores (Kuenzer, 2002) e de trabalhadores em geral (Zarifian, 2001) que mostram que a qualificação individual tem impacto reduzido sobre a qualidade do trabalho, quando não se insere em uma dinâmica mais ampla e intencional de qualificação do coletivo de professores a partir da escola, compreendida enquanto totalidade, uma vez que a qualidade do trabalho da escola resulta do trabalho coletivo dos profissionais que a integram. Não se está dizendo, com isso, que a qualificação deve se dar no trabalho, mas sim que é preciso desenvolver processos intencionais e sistematizados que envolvam os docentes que atuam na mesma escola ou pelo menos no mesmo processo pedagógico, uma vez que, pela via do trabalho individual, não existe possibilidade de transformação.

Com relação ao PNE para o período de 2011/2020, é preciso destacar as metas 15, 16, 17 e 18, que têm como objeto a universalização da formação dos docentes da educação básica em cursos de licenciatura na área de atuação; a formação de 50\% dos professores em exercício na educação básica em pós-graduação lato e stricto sensu; a garantia de formação continuada a todos em sua área de atuação; a compatibilização permanente dos salários com as carreiras que demandam nível equivalente de formação escolar (11 anos) e a existência de planos de carreira em todos os sistemas de ensino no prazo de dois anos.

Uma estratégia importante elencada na Meta 15 é a promoção da reforma curricular dos cursos de licenciatura, "de forma a assegurar o foco no aprendizado do estudante, dividindo a carga horária em formação geral, formação na área do saber e didática específica" (estratégia 15.7). Esta estratégia é fundamental, uma vez que as diretrizes curriculares para a formação de professores da educação básica remonta a 2002 (Resoluções n. 01/2002 e 02/2002 do сP/CNE) e têm sido objeto de críticas consistentes desde então, principalmente em face do aligeiramento da formação, resultante da diminuição da carga horária de formação específica e do caráter pragmatista da formação pedagógica, centrada nas práticas sem adequada formação teórica, principalmente nos fundamentos das Ciências da Educação (Kuenzer, 2010a).

Em que pese a intenção de promover a licenciatura ao status de curso com identidade, em substituição ao caráter de complementaridade do bacharelado, o que se verifica é que o modelo anterior não foi completamente superado, mantendo-se mediante estratégias de organização curricular. Ademais, os indicadores de permanência e de qualidade têm evidenciado a progressiva desqualificação do ensino médio, constatada inclusive pela expressiva diminuição de matrículas nos últimos seis anos (Kuenzer, 2010b). Evidentemente, não se trata de responsabilizar o professor por essa desqualificação, mas, certamente, a precarização de sua formação nos últimos anos é um fator relevante a ser considerado. 
Por fim, com relação à qualidade da formação docente, há um fator bastante preocupante: segundo os dados do Censo Escolar de 2009, do total dos professores de educação básica matriculados no ensino superior, em cursos de graduação, 45,8\% estão em cursos de educação a distância, sendo que mais de 50\% das matriculas são em cursos de Pedagogia, seguido dos cursos de Letras, Matemática e História. Embora a oferta de cursos de formação a distância faça parte das políticas dos últimos governos, urge a necessidade de uma rigorosa avaliação da qualidade destas propostas, uma vez que a obrigatoriedade da formação em licenciatura pela legislação em vigor pode estar levando a soluções meramente certificatórias, sem impacto relevante sobre a qualidade do ensino médio.

A breve análise dos dados, das políticas e das diretrizes aponta para a necessidade de efetivo investimento em políticas que integrem formação, carreira, remuneração e condições dignas de trabalho, para enfrentar uma histórica realidade de escassez, inadequação e desprofissionalização, com seus severos impactos sobre a qualidade do ensino médio, cujas matriculas decrescem a cada ano, assim como não melhoram os indicadores de permanência e de sucesso.

\section{O campo de formação de professores: as dimensões pedagógicas das relações sociais e produtivas}

De modo geral, quando se trata da formação de professores, o entendimento corrente é de que esse processo se resume a percursos formativos sistematicamente desenvolvidos em cursos de formação, em instituições de ensino superior. E, em consequência, as políticas têm como objeto a formação inicial e não integram as políticas relativas ao trabalho docente, em especial no que diz respeito à profissionalização e às condições de trabalho, que, de modo geral, são tratadas em outra esfera, a do financiamento.

Ao circunscrever a formação a cursos, além de atribuir a eles um papel que excede seus próprios limites, deixam de ser consideradas as dimensões pedagógicas presentes nas relações sociais e produtivas e, em particular, no trabalho docente, certamente mais efetivas do ponto de vista formativo que os próprios cursos de formação. Ou, como afirma Mészáros (2008), retomando os clássicos do materialismo histórico, a educação formal não é a força ideologicamente primária que consolida as relações de exploração capitalistas; os processos de internalização ocorrem, primariamente, no bojo das próprias relações sociais capitalistas... A pedagogia vem da fábrica, como afirma Gramsci (1978).

A esses processos amplamente pedagógicos, que visam à formação de subjetividades favoráveis à exploração capitalista, articulam-se processos especificamente 
pedagógicos que ocorrem nas instituições escolares. Estes, tais como os processos primários, têm como função precípua a produção de consensos, na linha da concepção gramsciana de disciplinamento (Kuenzer, 1985). E, assim sendo, não há como esperar que a sociedade da mercadoria estimule, produza, ou apenas referende propostas pedagógicas, incluindo as de formação de professores, que possam levar ao rompimento com a lógica mercantil.

Dessa forma, o debate sobre formação de professores permanece nos limites da lógica da reprodução capitalista, sem a necessária compreensão do seu caráter ideológico; a consequência mais imediata desta compreensão parcial é a crença de que, com um bom percurso formativo, inevitavelmente teremos bons professores. $\mathrm{O}$ caráter reducionista e simplificador desta concepção resulta da desconsideração da relação entre as esferas de produção e de reprodução das relações capitalistas, cujo resultado elide a constatação de que a formação só se materializa na ação docente que ocorre em situações concretas determinadas. Assim, é fácil culpar o professor, a proposta de formação e a instituição que o formou pelos parcos resultados de seu trabalho com alunos, em escolas que se propõem a atender os filhos dos que vivem do trabalho, com uma proposta pedagógica burguesa e sem condições mínimas de trabalho, incluindo a parca remuneração e a desvalorização social.

Outra lógica, portanto, é necessária, ao se pretender avançar nos espaços possíveis das contradições, na compreensão e na formulação de políticas e propostas de formação docente, considerados os limites já expostos, que se proponham a desenvolver consciências críticas e a desvelar as dimensões ideológicas da educação para o capital.

Essa outra lógica implica a análise das propostas de formação a partir da realidade do trabalho docente inserido no modo de produção capitalista, a partir do entendimento das dimensões pedagógicas das relações sociais e produtivas, com base no pressuposto da indiscutível relação entre os processos educacionais e os processos mais abrangentes de reprodução que ocorrem na sociedade.

Assim, a pergunta que se faz é a seguinte: Como as relações sociais capitalistas formam o professor no exercício do trabalho docente? E, a partir desse processo formativo, quais as possibilidades de uma prática comprometida com o campo do trabalho?

\section{As dimensões educativas do trabalho docente}

Para compreender como as relações sociais e produtivas formam o professor, torna-se necessário apontar as categorias que constituem o trabalho docente no capitalismo, identificando as contradições que poderão se constituir em dimensões formativas contra-hegemônicas. 


\section{O trabalho docente se inscreve no âmbito do trabalho capitalista}

O primeiro pressuposto teórico a ser considerado na análise do trabalho docente é que este é parte da totalidade constituída pelo trabalho no capitalismo, estando submetido, portanto, à sua lógica e às suas contradições. O que vale dizer que o trabalho docente não escapa à dupla face do trabalho capitalista: produzir valores de uso e valores de troca (Kuenzer \& Caldas, 2009).

Estas duas dimensões, de produção de valor de uso e de valor de troca, não se opõem, mas sim guardam uma relação dialética entre si, compondo uma totalidade por contradição, em que, ao mesmo tempo, se negam e se afirmam, fazendo do trabalho um exercício qualificador, prazeroso e, ao mesmo tempo, desqualificador, explorador, causador de sofrimento.

Decorre dessa afirmação que o trabalho docente, sob a égide do capitalismo, não escapa à lógica da acumulação do capital, direta ou indiretamente, pela compra da força de trabalho do professor e pela natureza de seu trabalho, que contraditoriamente forma sujeitos que atenderão às demandas do trabalho capitalista, cuja inclusão depende do disciplinamento para o qual a escola contribui. Ao mesmo tempo, o trabalho docente contribui, diretamente ou indiretamente, para a produção de ciência e tecnologia, pesquisando ou formando pesquisadores, e assim por diante. Ou seja, embora a finalidade do seu trabalho seja a formação humana, ele está atravessado pelas mesmas contradições que caracterizam o capitalismo.

Contudo, é por meio do trabalho que o professor, como os demais trabalhadores, ao mesmo tempo em que é submetido pelo capital ao processo de produção de valor - para a própria valorização desse mesmo capital, e não em benefício dos trabalhadores -, pode contribuir para a transformação desta mesma realidade, formando consciências capazes de compreender criticamente as relações capitalistas com vistas à sua superação.

Há, ainda, outra dimensão do trabalho capitalista que precisa ser considerada: em que pesem os fatores de alienação, é preciso considerar que a unidade rompida entre decisão e ação precisa ser recomposta no processo de trabalho, sem que se altere a condição que a gerou: a propriedade privada dos meios de produção. Esta necessidade, além de colocar para o capitalista a necessidade de rigoroso controle, aponta para o fato de que a geração do excedente depende, também, da capacidade multilateral dos seres humanos, do caráter inteligente e proposital que reveste sua ação de infinita adaptabilidade. Ou seja, a realização do trabalho capitalista depende da anuência do trabalhador, o que o torna artífice da própria exploração.

Esta característica é cada vez mais acentuada nas novas formas de organização e gestão do trabalho, onde a fragmentação taylorista-fordista, que ata o trabalhador 
ao exercício das mesmas ocupações ao longo de sua existência, é substituída por procedimentos mais ampliados, flexíveis e intelectualizados, que demandam conhecimento da totalidade do trabalho, e não mais apenas da parte, e que, ao mesmo tempo, ampliam as possibilidades de participação, de decisão e de controle do próprio trabalho, exigindo trabalhadores de novo tipo, com sólida base de educação geral a partir da qual se construirá uma formação profissional densa e continuada.

Ou seja, quanto mais abstrato o trabalho, maior a necessidade de adesão do trabalhador; contudo, contraditoriamente, também se ampliam as necessidades de acesso ao conhecimento.

Nesse sentido, o professor é ao mesmo tempo objeto e sujeito de formação: objeto, enquanto sua formação e exercício do seu trabalho implicam uma boa dose de adesão ao projeto capitalista; sujeito, porquanto, ao responder às demandas derivadas da crescente intelectualização do trabalho a partir de uma formação que lhe desenvolva a capacidade de análise e intervenção na realidade, pode contribuir para a formação de sujeitos capazes de formular, pelas mediações do conhecimento e da organização coletiva, outro projeto de sociedade. O que, contraditoriamente, também lhe demanda aportes crescentes de conhecimento, mediante a continuidade de sua formação ao longo de sua prática laboral.

Assim, as propostas curriculares de formação de professores podem estimular as práticas revolucionárias ou retardá-las, à medida que permitam ou não a compreensão do mundo do trabalho capitalista com todas as suas contradições; que possibilitem o desenvolvimento de práticas conservadoras ou estimulem o desenvolvimento de sujeitos críticos e criativos, comprometidos com a construção de outras relações sociais. Portanto, a proposta pedagógica tem papel fundamental a desempenhar na formação e profissionalização de professores que, por sua vez, vão formar homens e mulheres através de propostas curriculares. A qualidade da formação, contudo, vai depender das concepções ontológicas e epistemológicas que sustentam essas propostas curriculares, a partir das quais se formulam diferentes concepções de homem, de trabalho e de sociedade.

\section{O trabalho docente é trabalho não material}

No caso dos professores, a contribuição para o processo de acumulação se dá a partir de uma característica muito peculiar do seu trabalho: a sua natureza não material, já que não é possível separar o produtor de seu produto. Esta natureza limita, de certa maneira, a realização do trabalho segundo o modo capitalista, que passa a se dar indiretamente, por diferentes mediações que "convençam" o trabalhador, pela força ou pela persuasão, a ser artífice da própria exploração, ao tempo que busca sua realização pessoal, vinculada a finalidades. Ou seja, no trabalho não 
material a subsunção do trabalho ao capital apresenta limites, com o que se ampliam as possibilidades de resistência e de autonomia.

O fato do trabalho do professor ser não material não significa que ele seja improdutivo; como já se afirmou anteriormente, ele se articula à lógica da acumulação, quer pela produção de excedente nas instituições privadas, quer pela atuação em currículos que segmentam a formação, reafirmando as diferenças de classe, quer pela reprodução de subjetividades disciplinadas com a qualificação necessária para atender as demandas do modo de produção capitalista.

Ao conceber o trabalho do professor como não material, inscrevendo-o no campo dos "serviços", é preciso diferenciar "serviço" como expressão para designar o valor de uso particular de um trabalho ou mesmo para uma troca entre o usuário e o trabalhador - dar aulas particulares, fazer atendimento domiciliar a um aluno doente - $\mathrm{e}$ "serviço" como expressão de uma relação de compra e venda de força de trabalho que se integre ao processo de produção de mercadorias, ao gerar um valor excedente que será apropriado pelo capitalista. Em ambos os casos, o trabalho é não material, não se separando do produtor, mas expressa relações sociais diferenciadas (Marx, 1978).

No primeiro caso, o professor atua como trabalhador autônomo e independente, que vende um trabalho ou serviço, decidindo quando, como fazer e qual o preço; nesta situação, o trabalho tende a ser mais qualificado, mais prazeroso e pode claramente expressar um compromisso de classe; no segundo caso, o professor vende sua força de trabalho para uma instituição, que passa a determinar seu trabalho em todas as dimensões, retribuindo-o por meio de um salário; nesta situação, o trabalho tende a ser mais controlado, intensificado, precarizado e, portanto, mais explorado, tendo em vista acumular o capital dos proprietários ou associados, no caso das empresas de ensino ou das cooperativas, ou controlar os gastos públicos, no caso das instituições públicas.

Muda a finalidade - prestar um serviço público ou vender um serviço como mercadoria -, mas as relações de assalariamento, com todas as suas consequências, incluindo a precarização e a intensificação, são as mesmas.

Caso a venda da força de trabalho se dê para instituições privadas, o espaço para o compromisso de classe é limitado pelos controles institucionais, com vistas à produtividade.

Já no caso do professor da escola pública, acentuam-se as contradições entre a intensificação e a precarização do seu trabalho e os compromissos de classe renovados cotidianamente pela prática social em que está inserido; neste caso, tem-se como hipótese que é possível identificar manifestações de organicidade com a classe trabalhadora, embora sejam escassas as oportunidades de práticas que materializem esse compromisso. 
De todo modo, tal como tem se dado a crescente privatização dos serviços educacionais, a tendência à sua mercantilização é uma característica cada vez mais presente, diminuindo as possibilidades de intervenção criativa e independente dos profissionais da área, mesmo considerando a natureza não material do trabalho docente, o que pode lhe conferir certo grau de autonomia. Isto porque os serviços educacionais, como os demais serviços, sofreram os impactos da crise do capitalismo no final do século passado e no início deste. Forçadas a se reorganizar para serem competitivas, inclusive na disputa pelos fundos públicos, as instituições educacionais públicas e privadas desencadearam estratégias próprias da reestruturação produtiva, não se diferenciando, neste sentido, das demais empresas, a não ser pela especificidade de seu processo de trabalho.

Assim, combinaram complexificação tecnológica com redução de força de trabalho, hierarquizada segundo novas combinações entre qualificação-desqualificação e quantidade de trabalhadores, além de incorporar mecanismos de descentralização, em particular, de terceirização, ou, no caso dos professores do setor público, de contratos precários para realizar tarefas específicas, por tempo determinado. Isso sem falar nos processos de educação a distância, onde o trabalho do professor gera maisvalia extraordinária, uma vez que tem contratos por tarefa, com tempo determinado, enquanto o produto de seu trabalho, na forma de videoaulas ou material impresso, se reproduz infinitamente.

Em decorrência, a potencial resistência deste tipo de trabalho não material a submeter-se às leis da exploração capitalista tende a cair por terra, uma vez que os docentes são, como os demais trabalhadores, atingidos pela crise do trabalho, que se materializa pela intensificação de atividades precarizadas. Em decorrência, os docentes acabam vendendo sua força de trabalho para, em condições precárias, objetivar um resultado com o qual, na maioria das vezes, não concordam. Ou seja, através de seu trabalho, objetivam um produto que é fruto de sua alienação, de sua própria transformação em mercadoria, e não o fruto da coincidência entre a sua subjetividade, a sua consciência e as condições materiais de existência, no sentido da construção de um projeto de transformação da sociedade.

Aos professores restaria a esperança de trabalhar nos espaços públicos, onde, em tese, a relação entre custos e benefícios seria regida por outra lógica - a do direito a um serviço público de qualidade - e não pela realização da lógica da mercadoria. Mas nem isso é possível nos Estados de tipo neoliberal que, ao materializar a lógica das políticas mínimas, por um lado, empurram parte de suas responsabilidades para o setor privado, na modalidade do público não estatal, e, por outro lado, reduzem a política de direitos a ações de filantropia.

Essa mesma lógica submete a prestação do serviço público à precarização e ao compartilhamento com a prestação dos serviços privados, mediante contratos com 
organizações não governamentais, o que leva as instituições que exercem funções públicas a ser regidas pelas leis do mercado.

\section{A condição do exercício do trabalho capitalista não material forma o pro- fessor para enfrentar uma dialética complexa que articula desistência e resistência, com o que se amplia seu sofrimento no trabalho.}

Para analisar esta afirmação, parte-se da concepção anteriormente explicitada que compreende o trabalho docente como produzido e reproduzido através da tensão dialética entre as determinações estruturais da realidade social e suas próprias determinações específicas, concepção esta que produz a alienação e, ao mesmo tempo, engendra espaços de autonomia relativa.

Em decorrência, compreende-se que as relações de dominação, presentes na sociedade e no trabalho, podem gerar, contraditoriamente, reações de desistência, aqui entendidas como perda de sentido do trabalho e descompromisso com a organização em que atuam e com os destinatários de seu trabalho (Codo, 1999), e comportamentos de resistência, no sentido crítico-emancipatório (Giroux, 1986), ou seja, como espaço de luta contra-hegemônica.

Compreende-se, também, que lutas ou conflitos nem sempre traduzem aspirações de transformação ou contestação à sociedade e podem simplesmente representar motivações particulares, em defesa de interesses individuais ou de espaços de poder (Giroux, 1983), muitas vezes sabiamente articulados em discursos que visam o "ocultamento da particularidade", conforme expressa Heller (2002, p. 86).

Esta análise também parte da compreensão de que desistência e resistência não são processos que se opõem de forma maniqueísta, mas que se manifestam na prática de cada professor como dimensões contraditórias, cuja objetivação depende das condições materiais que estão dadas (Kuenzer \& Caldas, 2009).

Considerados esses pressupostos, é possível afirmar que, se do ponto de vista da mercantilização, os trabalhadores da educação não se diferenciam dos demais, sendo igualmente superexplorados, o fato de serem trabalhadores não materiais lhes confere especificidades que aumentam as possibilidades de sofrimento no trabalho e, em consequência, maior vulnerabilidade às doenças ocupacionais e à desistência (Codo, 1999). E mais, que os cursos de formação, ao tratar o trabalho docente de forma romantizada, não preparam os professores para enfrentar o sofrimento e a síndrome da desistência.

Esta condição se acentua no regime de acumulação flexível, onde a crise do trabalho leva os trabalhadores a se submeterem pacificamente ao sofrimento e ainda a justificá-lo, para manterem-se empregados (Dejours, 1999). Segundo este autor, 
são três a mudanças na organização do trabalho que intensificam o sofrimento, todas presentes no trabalho docente: a avaliação individual, a introdução de técnicas vinculadas à qualidade total e a terceirização. Estes dois últimos pontos têm sido objeto de discussão nas organizações dos trabalhadores da educação. A avaliação individual está no plano atual dos debates a partir da Prova Nacional para o ingresso na carreira docente, processo em curso no Ministério de Educação, por intermédio do INEP.

Para o autor, a avaliação individual põe organizações e trabalhadores em concorrência, e se vagas, promoções ou prêmios estiverem em jogo, ou a manutenção do emprego, a competição se acentua, estimulada pela insegurança e pelo medo. Em consequência, alteram-se as relações de trabalho, destruindo-se os laços de solidariedade e até de pertencimento; os trabalhadores se isolam, e individualizam suas práticas; abre-se o espaço para o denuncismo, para o assédio, para as práticas de bullying e para as doenças ocupacionais (Dejours, 2010). No caso do trabalho docente, as consequências do esgarçamento das relações sociais são mais perversas, uma vez que, neste caso, não pode haver trabalho pedagógico de qualidade sem envolvimento pessoal e trabalho coletivo.

Para Codo (op. cit.), a síndrome da desistência pode ser definida como resultante do sofrimento decorrente da contradição entre a consciência do que pode e deve fazer e o que efetivamente se consegue fazer, "entre o céu de possibilidades e o inferno dos limites estruturais, entre a vitória e a frustração; é a síndrome de um trabalho que voltou a ser trabalho, mas que ainda não deixou de ser mercadoria" (Codo, 1999, p. 13).

A concepção do autor remete à discussão levada a efeito nos itens anteriores deste texto: o trabalho do professor se objetiva na tensão entre trabalho em geral, qualificador, transformador, prazeroso, e trabalho capitalista, mercadoria comprada para valorizar o capital. Esta tensão se acentua pelo caráter não material do seu trabalho, que, ao não se separar do produtor, reafirma o espaço da consciência e da subjetividade e, assim, o poder do trabalhador, ao mesmo tempo em que cada vez mais o elimina, em face da progressiva institucionalização dos serviços educacionais ou de sua crescente precarização, a partir da lógica da acumulação capitalista, com o que se diminuem os espaços de intervenção do professor. Ou seja, no trabalho docente acentua-se a tensão entre subjetividade e objetivação.

Esta contradição, que faz parte da natureza do trabalho não material, é uma das condições que pode trazer sofrimento e não realização, se não for adequadamente enfrentada, quer pela qualificação dos profissionais, quer pelas formas de organização coletiva do trabalho. Esta dimensão, específica do trabalho não material, aliada a outras, típicas de todas as formas de assalariamento (baixos salários, condições precárias de trabalho, intensificação, estresse, medo de perder emprego, 
autoritarismo e outras), pode causar a síndrome da desistência, que envolve esgotamento emocional, desenvolvimento de atitudes negativas em relação ao trabalho, falta de envolvimento pessoal no trabalho e assim por diante (idem, ibid., p. 238), com severos impactos sobre a qualidade de ensino.

A precarização da qualidade do ensino médio, decorrente das condições materiais e de trabalho inadequadas, a par da síndrome da desistência de um bom número de professores, é uma dimensão que não será resolvida com os cursos de formação inicial e continuada de docentes, ainda mais com a concepção que está presente nas diretrizes nacionais para essa formação. Ao contrário, resulta e só poderá ser enfrentada no plano da transformação das condições materiais que a determinam, para o que uma nova concepção de formação docente será necessária.

\section{Considerações finais}

A formação de professores do ensino médio deve articular conhecimentos sobre o mundo do trabalho, conhecimentos científico-tecnológicos sobre a área ser ensinada, conhecimentos pedagógicos, formação em pesquisa e experiência no trabalho docente.

A análise levada a efeito ao longo do texto conduz a algumas considerações importantes. Talvez a mais relevante seja a de que a formação de professores, à medida que se constitui em estratégia de reprodução do capital, não se separa da esfera da produção, com o que há propostas diferenciadas e desiguais que atendem a diferentes necessidades de formação para as cadeias produtivas; também, decorre desta compreensão que a autonomia relativa das propostas pedagógicas resta reduzida. Há que se esclarecer, portanto, de que formação e para que professor está se tratando.

No contexto deste artigo, o objeto é a formação de professores para ensinar os que vivem do trabalho e que, historicamente, vêm sendo excluídos dos direitos ao trabalho, à educação e dos demais direitos sociais.

Deste ponto de vista, o enfrentamento da definição de políticas, diretrizes e propostas de formação de professores torna-se mais complexo. Em primeiro lugar, esta tem que ser uma construção coletiva a ser realizada pelas organizações dos trabalhadores da educação e de suas associações científicas, mediante a ampliação do debate, cujo caráter deve ser permanente, buscando intervir, no que for possível, na proposta de formação hegemônica, sem desconsiderar os limites desta atuação.

Em segundo lugar, a objetivação das propostas construídas coletivamente deve ser assumida, pelo menos em parte, por essas próprias organizações e associações, 
como espaços formativos alternativos aos espaços atravessados pela lógica burguesa, comprometidos com o exercício da crítica à educação capitalista.

A tarefa a ser realizada pela organização coletiva dos profissionais da educação é traduzir o processo pedagógico em curso, elucidar a quem ele serve, explicitar suas contradições e, com base nas condições concretas dadas, promover as necessárias articulações para construir coletivamente alternativas que ponham a educação a serviço do desenvolvimento de outras relações sociais, verdadeiramente democráticas.

Essa rápida análise permite identificar a primeira dimensão a ser considerada na formação do professor comprometido com o campo do trabalho: a capacidade de, apoiando-se nas ciências humanas, sociais e econômicas, compreender as mudanças ocorridas no mundo do trabalho, construindo categorias de análise que lhe permitam apreender as dimensões pedagógicas presentes nas relações sociais e produtivas, de modo a identificar as novas demandas de educação e a que interesses elas se vinculam. Ou seja, compreender historicamente os processos de formação humana em suas articulações com a vida social e produtiva, as teorias e os processos pedagógicos, de modo a ser capaz de produzir conhecimento em educação e intervir de maneira competente nos processos pedagógicos amplos e específicos, institucionais e não institucionais, com base em uma determinada concepção de sociedade.

Embora seu objeto de estudo sejam todos os processos pedagógicos que ocorrem no âmbito da sociedade e do trabalho, a especificidade de sua função se define pela sua intervenção em processos pedagógicos intencionais e sistematizados. É pela mediação desses processos sistematizados que o conhecimento social e historicamente produzido se transforma em saber escolar; que os conteúdos são selecionados e organizados em formas metodológicas adequadas; que são construídas formas democráticas de organização e gestão dos sistemas de ensino nos vários níveis e modalidades. É através deles que o professor participa do esforço coletivo para construir projetos educativos, escolares ou não escolares, que expressem os desejos da classe social com a qual está comprometido (Kuenzer, 1998).

Essas afirmações conduzem à necessidade de considerar, na formação do professor, estudos e práticas que lhe permitam apropriar-se das diferentes formas de leitura e interpretação da realidade que se constituem em objeto de vários campos do conhecimento, mas em particular da filosofia, da história, da sociologia e da economia, bem como estabelecer interlocução com os vários especialistas.

Outra dimensão a considerar na formação dos professores diz respeito à mudança de eixo que ocorre na passagem do taylorismo/fordismo para as novas formas de organização e gestão dos processos sociais e produtivos, no que se refere à relação entre homem e conhecimento, que agora não passa mais pelos modos de fazer, 
como memorização e repetição de procedimentos relativamente rígidos e estáveis. Pelo contrário, essa relação passa agora pelas atividades intelectuais, exigindo o desenvolvimento de competências cognitivas que só se desenvolvem em situações de aprendizagem que possibilitem interação significativa e permanente entre o aluno e o conhecimento. Em decorrência, torna-se necessário não só o trato com conteúdos, mas principalmente com formas metodológicas que permitam a utilização do conhecimento sócio-histórico e científico-tecnológico para intervir na realidade, criando novos conhecimentos.

Para tanto, o professor precisará adquirir a necessária competência para, com base nas leituras da realidade e no conhecimento dos saberes tácitos e experiências dos alunos, selecionar conteúdos, organizar situações de aprendizagem em que as interações entre aluno e conhecimento se estabeleçam de modo a desenvolver as capacidades de leitura e interpretação do texto e da realidade, comunicação, análise, síntese, crítica, criação, trabalho coletivo, e assim por diante.

Enfim, ele deverá promover situações para que seus alunos transitem do senso comum para o comportamento científico.

Para tanto, ao professor não basta conhecer o conteúdo específico de sua área; ele deverá ser capaz de transpô-lo para situações educativas, para o que deverá conhecer os modos como se dá a aprendizagem em cada etapa do desenvolvimento humano, as formas de organizar o processo de aprendizagem e os procedimentos metodológicos próprios a cada conteúdo. Para que esse tipo de formação seja possível, ela precisa ocorrer, no mínimo, em cursos de graduação em instituições que articulem diversos campos do conhecimento e atividade investigativa, de modo a assegurar formação interdisciplinar complementada por formação em pesquisa.

Caracterizadas as suas atribuições e as preliminares demandas de formação, a próxima questão a enfrentar será o aprofundamento da discussão apontada na Introdução: a complexificação da sua formação a partir da definição de a quem se destina o seu trabalho.

A análise do regime de acumulação flexível mostra que a mais significativa transformação decorrente da nova etapa de acumulação ocorreu no âmbito do trabalho, que deixou de ser estável com as relações de assalariamento, passando a assumir novas e velhas formas, que vão da terceirização ao resgate das antigas formas de trabalho domiciliar, porém, cada vez mais informal e precarizado, diminuindo dramaticamente os postos de trabalho e tornando o desemprego uma tendência que parece ser irreversível.

Dessa análise decorre que a norma será lidar com trabalhadores e seus filhos, precarizados e excluídos. As pesquisas já têm mostrado que a precarização econômica, ao inviabilizar experiências socioculturais variadas e significativas, conduz a 
uma precarização cultural que se expressa nas dificuldades de linguagem, de raciocínio lógico-matemático e de relação com o conhecimento formalizado, que dificilmente a escola consegue suprir.

Esse dado, aliado ao insuficiente investimento público em educação, traz mais um desafio ao professor, exigindo maior rigor na sua formação: ter competência para suprir, em uma escola precarizada, com condições de trabalho cada vez piores, as deficiências culturais e cognitivas decorrentes da origem de classe da maioria dos alunos. Evidentemente, a ninguém ocorreria imaginar que a escola pública pudesse resolver essa questão, o que significaria atribuir-lhe o poder de mudar as estruturas que determinam as desigualdades sociais.

Contudo, é inegável o seu compromisso e, portanto, de seus professores, com o enfrentamento das desigualdades, pela via da democratização dos conhecimentos que minimamente permitirão aos alunos participar, da melhor forma possível, da vida social e produtiva.

Para fazê-lo, o professor deverá estar capacitado para trabalhar com as diferenças, desde a sua correta identificação até a seleção de conteúdos, caminhos metodológicos e formas de avaliação, de modo a minimizá-las, no que diz respeito às relações com o conhecimento e ao desenvolvimento das competências cognitivas complexas. E sem poder contar com os recursos necessários e com a devida retribuição salarial, o que vai lhe exigir mais esforço, competência, criatividade e compromisso.

Não menos importante é a formação para articular ciência, cultura e trabalho, particularmente em face da retomada da concepção de educação profissional integrada ao ensino médio, nas modalidades regular e PROEJA.

Em resumo, as mudanças ocorridas no mundo do trabalho e das relações sociais apontam na direção de uma formação mais rigorosa, com sólidos fundamentos gerais, comum a todos os professores da educação básica, a ser complementada, no caso dos professores dos conteúdos específicos de educação profissional integrada ao ensino médio, com conhecimentos e práticas científico-tecnológicas e sócio-históricas da área de trabalho a ser ensinada. Para tanto, a formação deverá contemplar os seguintes eixos:

- contextual, articulando os conhecimentos sobre educação, economia, política e sociedade, e suas relações, tomadas em seu desenvolvimento histórico;

- epistemológico, integrando as teorias e princípios que regem a produção social do conhecimento; 
- institucional, contemplando as formas de organização dos espaços e processos educativos escolares e não escolares;

- pedagógico, integrando os conhecimentos relativos a teorias e práticas pedagógicas, gerais e específicas, incluindo cognição, aprendizagem e desenvolvimento humano;

- práxico, de modo a integrar conhecimento científico, conhecimento tácito e prática social;

- ético, compreendendo as finalidades e responsabilidades sociais e individuais no campo da educação, em sua relação com a construção de relações sociais e produtivas, segundo os princípios da solidariedade, da democracia e da justiça social;

- investigativo, comprometido com o desenvolvimento das competências em pesquisa, tendo em vista o avanço conceitual na área do trabalho e da educação.

A compreensão do trabalho docente em seus limites e possibilidades, a partir desses eixos, devidamente sustentados pelas categorias do método da economia política e pelo compromisso com a construção coletiva de um projeto pedagógico mais orgânico às necessidades dos que vivem do trabalho, é um dos caminhos possíveis para a construção de propostas de formação de professores alternativas à lógica capitalista de disciplinamento.

\section{Referências}

BRASIL. Ministério da Educação. Instituto Nacional de Estudos e Pesquisas Educacionais (INEP). Censo Escolar da Educação Básica 2007. Disponível em: <www.inep. gov.br>

BRASIL. Ministério da Educação. Instituto Nacional de Estudos e Pesquisas Educacionais (INEP). Censo Escolar da Educação Básica 2009. Disponível em: <www.inep. gov.br>

BRASIL. Ministério da Educação. Instituto Nacional de Estudos e Pesquisas Educacionais (INEP). Estudo exploratório sobre o professor brasileiro. 2009. Disponível em: <www.inep.gov.br>

CODO, W. Educação: carinho e trabalho. Rio de Janeiro: Vozes, 1999.

DEJOURS, C. A banalização da injustiça social. Rio de Janeiro: FGV, 1999. 
DEJOURS, C. Um suicídio no trabalho é uma mensagem brutal. Entrevista concedida a Ana Gerschenfeld. 2010. Disponível em: <www.publico.pt $>$

GIROUX, H. Teoria crítica e resistência em educação. Petrópolis: Vozes, 1986.

GRAMSCI, A. Maquiavel, a política e o Estado moderno. Rio de Janeiro: Civilização Brasileira, 1978.

HELLER, A. Sociología de la vida cotidiana. Barcelona: Península, 2002.

KUENZER, A. Pedagogia da fábrica. São Paulo: Cortez, 1985.

KUENZER, A. A formação de educadores no contexto das mudanças no mundo do trabalho: novos desafios para as faculdades de educação. Educação \& Sociedade, Campinas, v. 19, n. 63, p. 105-111, ago. 1998.

KUENZER, A. A escola desnuda: reflexões sobre a possibilidade de construir o ensino médio para os que vivem do trabalho. In: Zibas, D.; Aguiar, M.A.; Bueno, M.S. (Org.). O ensino médio e a reforma da educação básica. Brasília, DF: Plano, 2002. p. 229-330.

KUENZER, A. Formação de professores para a educação profissional e tecnológica. In: Dalben, A.I.L.F. et al. (Org.). Convergências e tensões no campo da formação e do trabalho docente. Belo Horizonte: Autêntica, 2010a. p. 497-518.

KUENZER, A. O ensino médio no Plano Nacional de Educação 2011/2020. Educação $\mathcal{E}$ Sociedade, Campinas, v. 31, n. 112, p. 851-873, jul./set. 2010b.

KUENZER, A.; CALDAS, A. Trabalho docente: comprometimento e desistência. In: Fidalgo, F; Oliveira, M.A.M. A intensificação do trabalho docente: tecnologias e produtividade. Campinas: Papirus, 2009. p. 19-38.

MARX, K.; ENGELS, F. A ideologia alemã. Lisboa: Martins Fontes, s/d.

MARX, K. O Capital. São Paulo: Ciências Humanas, 1978. Livro 1, cap. 6 inédito.

MÉSZÁROS, I. A educação para além do capital. Campinas: Boitempo, 2008.

URBANETZ, S. A constituição do docente para a educação profissional. 2011. Tese (Doutorado em Educação) - Programa de Pós-Graduação em Educação, Universidade Federal do Paraná, Curitiba.

ZARIFIAN, P. Objetivo competência: por uma nova lógica. São Paulo: Atlas, 2001.

Recebido em 19 de julho de 2011.

Aprovado em 3 de agosto de 2011. 